\title{
Brincar na creche: um olhar sobre teses e dissertações brasileiras ${ }^{1}$
}

Fabrícia Soares Araújo de Sá ${ }^{2}$

Orcid: http://orcid.org/0000-0003-3978-7819

Sílvia Adriana Rodrigues ${ }^{3}$

Orcid: http://orcid.org/0000-0003-12493976

Rosimary Alves de Souza Garcia ${ }^{4}$

Orcid: http://orcid.org/0000-0002-9697-7590

\begin{abstract}
Resumo
Este texto é um recorte da pesquisa desenvolvida com objetivo geral de mapear e compreender as concepções do brincar na Educação Infantil, especificamente na creche, discutidas em teses e dissertações produzidas na área da Educação. A investigação, com abordagem quanti-qualitativa, do tipo Estado do Conhecimento, teve como fonte para obtenção dos dados a "Biblioteca Digital de Teses e Dissertações”. A busca, com delimitação temporal no período de 1999 a 2018 , resultou em um número final de quatro produções, indicando claramente a quase inexistência de pesquisas envolvendo o brincar que tenha como contexto a creche. Acreditamos que o cenário revelado denuncia o descaso ainda sofrido por esse espaço quando se trata de uma abordagem educacional/pedagógica envolvendo suas práticas cotidianas também nos trabalhos acadêmicos; bem como, certa desvalorização do brincar no espaço de atendimento educativo.
\end{abstract}

Palavras-chave: Importância do brincar. Estado do conhecimento. Brincar na creche.

\begin{abstract}
This text is an excerpt of the research developed with the general objective of mapping and understanding the conceptions of playing in Early Childhood Education, specifically in daycare, discussed in theses and dissertations produced in the field of Education. The investigation, with a quanti-qualitative approach, of the State of Knowledge type, had as a source to obtain the data the "Digital Library of Theses and Dissertations". The search, with temporal delimitation in the period from 1999 to 2018, resulted in a final number of four productions, clearly indicating the almost non-existence of researches involving playing that has the day care center as a context. We believe this scenario reveals the neglect still suffered by this space when it comes to an educational/pedagogical approach involving their daily practices in academic place as well; as well as a certain devaluation of playing in the educational space.
\end{abstract}

Keywords: Importance of playing. State of knowledge. Playing at the daycare.

\footnotetext{
${ }^{1}$ O presente trabalho foi realizado com apoio da a Universidade Federal de Mato Grosso do Sul e da Coordenação de Aperfeiçoamento de Pessoal de Nível Superior - Brasil (CAPES) - Código de Financiamento 001

${ }^{2}$ Mestre em Educação. Especialista em Educação da Rede Municipal de Ensino de Três Lagoas-MS. E-mail: fabriciatls@hotmail.com.

${ }^{3}$ Doutora em Educação. Professora Adjunta da Universidade Federal do Mato Grosso do Sul. E-mail: silvia.rodrigues@ufms.br.

${ }^{4}$ Mestre em Educação. Professora Coordenadora da Rede Municipal de Ensino de Três Lagoas-MS. E-mail: rosimaryalvessouzagarcia2016@gmail.com.
} 


\section{Introdução}

A investigação ora apresentada partiu do pressuposto de que não é sem razão que o brincar se configura como um dos eixos das práticas pedagógicas em diferentes documentos que regulamentam e norteiam o trabalho educativo em instituições de Educação Infantil (EI), pois ele se constitui como um elemento essencial para impulsionar processos de desenvolvimento e aprendizagem infantil. Assim, faz-se importante esclarecer que:

[...] a referência ao brincar aqui abordada, não está limitada à promoção de brincadeiras de contar, reconhecer números, letras e memorizar conteúdos das diferentes áreas do conhecimento científico como se observa nas práticas habituais das instituições educativas. Entende-se aqui o brincar como processo que oportuniza o socializar, aprender a negociar para conseguir o que quer, a ganhar e a perder as disputas, a esperar, cooperar e a evoluir no processo de adequado desenvolvimento global (RODRIGUES, 2016, p. 55).

Além disso, conforme aponta Borba (2006, p. 39), entendemos o brincar como: “[...] um dos pilares da constituição de culturas da infância, compreendidas como significações e formas de ação social específicas que estruturam as relações das crianças entre si, bem como os modos pelos quais interpretam, representam e agem sobre o mundo".

Nessa perspectiva, na história da Educação Infantil brasileira, há diferentes textos legais que reconhecem e preconizam a importância e a necessidade de o brincar fazer parte do cotidiano pedagógico da EI; dentre eles temos um dos Cadernos Carinhas de 1995, intitulado: Critérios para um atendimento em creches e pré-escolas que respeite os direitos fundamentais das crianças, lançado pela Coordenadoria Geral da Educação Infantil (COEDI), reeditado em 2009, no qual são trazidos os princípios relacionados a aspectos físicos e culturais das crianças, relevantes para a organização e propostas de ações das instituições de atendimento educativo de crianças bem pequenas e onde o brincar ganha destaque como elemento pedagógico, pela primeira vez, em um texto oficial.

Outro documento que merece destaque - apesar das polêmicas que envolvem sua formulação, como também do seu uso indiscriminado por instituições e profissionais na elaboração de propostas pedagógicas, tendo em vista ser um documento sugestivo com algumas falhas internas - é o Referencial Curricular Nacional para a Educação Infantil RCNEI (BRASIL, 1998). O referido material traz, ainda que de forma "cacofônica", o brincar e a brincadeira como elementos que necessitam (e devem) permear as práticas pedagógicas da Educação Infantil, devido ao seu potencial de promover diversas aprendizagens e o desenvolvimento infantil de forma geral.

Com o mesmo espírito, temos as Diretrizes Curriculares Nacionais para a Educação Infantil (DCNEI), aprovada sua primeira versão em 1999 (BRASIL, 1999), e a sua revisão no ano de 2009, a qual, nessa última redação, contém a indicação de que a especificidade da ação pedagógica junto às crianças da EI é a centralidade das brincadeiras e das relações sociais (BRASIL, 2010); tal apontamento implica entender/assumir que todas as ações no interior das instituições educativas (creches e pré-escolas) devem ter caráter relacional e lúdico (RODRIGUES, 2016). De acordo com a mesma autora citada "[...] têm-se então os elementos estruturantes da prática pedagógica das creches: o brincar e o cuidar-educar articulados como uma unidade que incorpora uma questão importante que é a das relações interpessoais - cujo valor é acentuado na creche [...]" (RODRIGUES, 2016, p. 52). Cabe destacar que as DCNEI é um documento mandatório; ou em outros termos, documento de base, obrigatório, para a elaboração de projetos pedagógicos e planos de ensino: “[...] cujo texto enfatiza o respeito às especificidades da educação infantil (creche e pré-escola) e das culturas infantis" (RODRIGUES, 2016, p. 66).

É possível, igualmente, citar outros documentos elaborados para nortear a Educação 
Infantil brasileira que abordam e valorizam o brincar, tais como: Parâmetros Nacionais de Qualidade para a Educação Infantil (BRASIL, 2006), além do manual Brinquedos e brincadeiras de creche, publicado em 2012 pelo Ministério da Educação (BRASIL, 2012). Dessa maneira, faz-se importante observar que, em termos legais, o brincar tem recebido o devido destaque e a valoração como elemento pedagógico no sentido amplo, como estratégia principal a ser empregada cotidianamente nas práticas educativas de creches e pré-escolas.

Tal cenário nos levou à questão tratada na investigação proposta: como a academia, especificamente os programas brasileiros de Pós-Graduação em Educação, tem tratado o brincar e temas correlatos como brinquedo, brincadeira e ludicidade no contexto educativo específico da creche? Salientamos que, para além do interesse sobre o quantitativo de estudos que já abordaram a temática da forma selecionada, temos como propósito identificar as tendências teórico-metodológicas e contribuições dos trabalhos já produzidos no interstício entre os anos de 1998 e 2018. É parte desse esforço que apresentamos nos limites do texto presente.

\section{Recortes metodológicos}

A pesquisa em tela seguiu a trilha de natureza quanti-qualitativa, inserida no campo bibliográfico. Tendo em vista a busca por identificar a tendência das discussões de um determinado objeto, no caso o brincar, em teses e dissertações produzidas em Programas de Pós-Graduação em Educação, a investigação se enquadra, ademais, como sendo do tipo Estado do Conhecimento. (LIMA; MIOTO, 2007; ROMANOWSKI; ENS, 2006).

De acordo com Romanowski e Ens (2006, p. 39), o valor de estudos dessa natureza está na possibilidade de trazer

[...] uma contribuição importante na constituição do campo teórico de uma área de conhecimento, pois procuram identificar os aportes significativos da construção da teoria e prática pedagógica, apontar as restrições sobre o campo em que se move a pesquisa, as suas lacunas de disseminação, identificar experiências inovadoras investigadas que apontem alternativas de solução para os problemas da prática e reconhecer as contribuições da pesquisa na constituição de propostas na área focalizada.

De forma complementar, Triviños (1987, p. 100) indica esse tipo de estudo, que permite ao pesquisador ir "[...] avaliando seus recursos humanos e materiais, as possibilidades de realização de seu trabalho, a utilidade que os resultados alcançados podem emprestar à determinada área do saber e da ação".

Desse modo, no que diz respeito à fonte para levantamento dos dados, selecionamos o site da Biblioteca Digital Brasileira de Teses e Dissertações (BDTD), por ser esse um banco de dados oficial, confiável, atualizado e com interface amigável, o que deu agilidade ao processo de levantamento dos trabalhos.

A delimitação temporal de 21 anos (1998 a 2018) foi pensada tendo em mente que o período traz como marcos a publicação de dois importantes documentos oficiais: o RCNEI (BRASIL, 1998) e a aprovação da Base Nacional Curricular Comum para a Educação Infantil - BNCC (BRASIL, 2018). Ressaltamos que tal documento aparece em nossa pesquisa apenas como um marco histórico, pois não coadunamos com a ideia defendida nele de restrição de habilidades por meio do desenvolvimento de competências individuais de forma fragmentada. Importante ainda indicar que nesse interstício temporal há a publicação de outro e mais importante documento: as Diretrizes Curriculares Nacionais para a Educação Infantil - sendo a primeira versão em 1999 e sua revisão e ampliação em 2009 (BRASIL, 1999, 2009). 
Por conseguinte, para a busca das teses e dissertações foram utilizados os descritores: brincar(es), brincadeira(s), brinquedo(s), lúdico(s) e ludicidade, isolados e também cruzados com os termos: educação infantil e creche. Convém esclarecermos que os trabalhos encontrados foram pré-selecionados com base na leitura dos títulos, palavras-chave, resumos e, em alguns casos, na consulta do texto completo.

Para o tratamento dos dados, recorreremos à técnica de Análise de Conteúdo de Laurence Bardin, entendendo-a como: “[...] um conjunto de técnicas de análise das comunicações que utiliza procedimentos sistemáticos e objetivos de descrição do conteúdo das mensagens [...]" (BARDIN, 1977, p. 38). A autora afirma que tal perspectiva metodológica tem como intenção a inferência de conhecimentos relativos às condições de produção, independentemente da natureza abordada (qualitativa ou quantitativa). Característica que exige do pesquisador trabalhar análogo a um detetive; ou seja, buscar interpretação e significação a partir de vestígios, manifestações de estados, dados e fenômenos.

Seguidos os passos da categorização descrita por Bardin (1997), temos a organização dos dados conforme apresentado a seguir.

\section{Apresentação dos dados}

Retomamos a informação de que para o levantamento de dados utilizamo-nos de descritores previamente escolhidos, com o intuito de mapear e quantificar os trabalhos já desenvolvidos no cenário da pesquisa científica. Assim, na primeira busca encontramos um total de 3.338 produções científicas. Ressaltamos que esse montante corresponde a produções de diferentes áreas de conhecimento (Psicologia, Enfermagem, Educação etc.), que, de alguma forma, abordam os descritores anteriormente mencionados, conforme apresentado no quadro a seguir.

Quadro 1 - Trabalhos encontrados por descritores na primeira seleção

\begin{tabular}{|l|c|}
\hline \multicolumn{1}{|c|}{ Descritores } & Quantidade \\
\hline Brincar(es) x Berçário & 11 \\
\hline Brincadeira (s) x Berçário & 16 \\
\hline Ludicidade/ Lúdico x Berçário & 9 \\
\hline Brinquedo x Berçário & 3 \\
\hline Jogo(s) x Berçário & 5 \\
\hline Brincar(es) x Creche & 74 \\
\hline Brincadeira(s) x Creche & 82 \\
\hline Ludicidade/ Lúdico x Creche & 50 \\
\hline Brinquedo x Creche & 27 \\
\hline Jogo(s) x Creche & 26 \\
\hline Brincar(es) x Educação Infantil & 371 \\
\hline Brincadeira (s) x Educação Infantil & 444 \\
\hline Ludicidade/ lúdico x Educação Infantil & 355 \\
\hline Brinquedo x Educação Infantil & 155 \\
\hline Jogo(s) x Educação Infantil & 358 \\
\hline Brincar(es) x Educação da Primeiríssima Infância & 1 \\
\hline Brincadeira (s) x Educação da Primeiríssima Infância & 0 \\
\hline Ludicidade/lúdico x Educação da Primeiríssima Infância & 2 \\
\hline Brinquedo x Educação da Primeiríssima Infância & 1 \\
\hline Jogo(s) x Educação da Primeiríssima Infância & 0 \\
\hline Brincar(es) Educação Infantil de 0 a 3 Anos & 187 \\
\hline Brincadeira(s) x Educação Infantil de 0 a 3 Anos & --- \\
\hline Ludicidade/ Lúdico x Educação Infantil de 0 a 3 Anos & 237 \\
\hline Brinquedo x Educação Infantil de 0 a 3 Anos & 89 \\
\hline Jogo(s) x Educação Infantil de 0 a 3 Anos & 491 \\
\hline
\end{tabular}




\begin{tabular}{|c|c|}
\hline Brincar(es) x Primeira Infância & 69 \\
\hline Brincadeira(s) x Primeira Infância & 77 \\
\hline Ludicidade/Lúdico x Primeira Infância & 68 \\
\hline Brinquedo x Primeira Infância & 41 \\
\hline Jogo(s) x Primeira Infância & 89 \\
\hline Total geral & 3.338 \\
\hline
\end{tabular}

Fonte: Elaborado pelas autoras (2020)

O segundo passo foi o refinamento dos dados encontrados com uso do filtro Educação, já que nossa proposta de pesquisa tem como foco esse contexto. Chegamos, então, a uma apuração bem inferior se comparada à primeira busca: um total de 241 produções (conforme apresentado no Quadro 2).

Quadro 2 - Trabalhos encontrados por descritores com filtro Educação

\begin{tabular}{|c|c|}
\hline Descritores & Quantidade \\
\hline Brincar(es) x Berçário & - \\
\hline Brincadeira(s) x Berçário & 1 \\
\hline Ludicidade/ Lúdico x Berçário & 1 \\
\hline Brinquedo x Berçário & - \\
\hline Jogo(s) x Berçário & - \\
\hline Brincar(es) x Creche & 1 \\
\hline Brincadeira(s) $x$ Creche & 4 \\
\hline Ludicidade/ Lúdico x Creche & 2 \\
\hline Brinquedo $\mathrm{x}$ Creche & 2 \\
\hline Jogo(s) x Creche & 2 \\
\hline Brincar(es) x Educação Infantil & 23 \\
\hline Brincadeira(s) x Educação Infantil & 32 \\
\hline Ludicidade/ Lúdico x Educação Infantil & 25 \\
\hline Brinquedo x Educação Infantil & 14 \\
\hline Jogo(s) x Educação Infantil & 20 \\
\hline Brincar(es) x Educação da Primeiríssima Infância & - \\
\hline Brincadeira (s) x Educação da Primeiríssima Infância & - \\
\hline Ludicidade/lúdico x Educação da Primeiríssima Infância & - \\
\hline Brinquedo x Educação da Primeiríssima Infância & - \\
\hline Jogo(s) x Educação da Primeiríssima Infância & - \\
\hline Brincar(es) Educação Infantil de 0 a 3 Anos & 16 \\
\hline Brincadeira (s) x Educação Infantil de 0 a 3 Anos & 23 \\
\hline Ludicidade/ Lúdico x Educação Infantil de 0 a 3 Anos & 20 \\
\hline Brinquedo $x$ Educação Infantil de 0 a 3 Anos & 05 \\
\hline Jogo(s) x Educação Infantil de 0 a 3 Anos & 29 \\
\hline Brincar(es) x Primeira Infância & 2 \\
\hline Brincadeira(s) x Primeira Infância & 8 \\
\hline Ludicidade/ Lúdico Primeira Infância & 4 \\
\hline Brinquedo x Primeira Infância & 2 \\
\hline Jogo(s) x Primeira Infância & 5 \\
\hline Total geral & 241 \\
\hline
\end{tabular}

Fonte: Elaborado pelas autoras (2020)

O próximo passo foi a revisão cuidadosa com o objetivo de detectar repetições, pois alguns trabalhos aparecem em diferentes descritores, sendo nesse movimento excluídos 142 deles, restando, assim, 99 produções.

Continuando a etapa de seleção, realizamos um quarto passo: a leitura atenta dos textos, com o objetivo de detectar se, eventualmente, as produções não abordavam o tema brincar e suas variações. 
Iniciamos essa tarefa com a leitura dos resumos e nos casos que esses não apresentavam todas as informações necessárias, recorremos ao trabalho completo. Após esse procedimento, excluímos mais 68 produções que não atendiam aos critérios de busca estabelecidos, persistindo, dessa maneira, 31 trabalhos.

$\mathrm{Na}$ sequência, voltamos o olhar detidamente para os 31 trabalhos, dessa vez com intuito de conferir se todos, de fato, abordavam o brincar na Educação Infantil especificamente no nível creche, visto que mesmo usando o filtro Educação Infantil foram encontrados vários trabalhos que discutiam o tema vinculando-o diretamente ao Ensino Fundamental - séries inicias. Enfatizamos que, durante nossa análise, foi possível constatar que a maior parte dos trabalhos selecionados nesse passo estavam relacionados às séries iniciais, excluímos, por consequência, 25 produções.

Chegamos, desse modo, à somatória de seis trabalhos que abordavam o brincar na Educação Infantil-creche. Contudo, numa nova análise dessas produções foi necessário excluir mais dois, porque eles abordavam apenas a pré-escola, não se encaixando em nossa delimitação; dessa forma, temos como resultado final quatro produções científicas que compõem o corpus de dados do estudo.

Cabe salientar que, entre os trabalhos selecionados, apenas um discute o brincar na faixa etária específica de atendimento em creche, os outros três contemplam os subníveis creche e pré-escola. A seguir, apresentamos o quadro com os dados de identificação das produções selecionadas.

Quadro 3 - Trabalhos encontrados por descritores com filtro Educação

\begin{tabular}{|c|l|l|c|c|c|c|}
\hline $\mathbf{N}^{\circ}$ & \multicolumn{1}{|c|}{ Título } & \multicolumn{1}{|c|}{ Tutor } & $\begin{array}{c}\text { Ano de } \\
\text { defesa }\end{array}$ & Instituição & Região \\
\hline 1 & $\begin{array}{l}\text { O brinquedo na } \\
\text { educação infantil como } \\
\text { promotor das culturas } \\
\text { da infância e } \\
\text { humanização. }\end{array}$ & $\begin{array}{l}\text { Larissa Aparecida } \\
\text { Trindade dos Santos }\end{array}$ & Dissertação & 2010 & UNESP & Sudeste \\
\hline 2 & $\begin{array}{l}\text { A brincadeira na } \\
\text { educação infantil: uma } \\
\text { experiência } \\
\text { pesquisa e intervenção }\end{array}$ & José Ricardo Silva & Dissertação & 2012 & UNESP & Sudeste \\
\hline 3 & $\begin{array}{l}\text { Participação de } \\
\text { crianças nas rotinas } \\
\text { da educação infantil }\end{array}$ & $\begin{array}{l}\text { Synara do Espirito } \\
\text { Santo Almeida }\end{array}$ & Dissertação & 2015 & UFS & Nordeste \\
\hline 4 & $\begin{array}{l}\text { Modos de brincar na } \\
\text { educação infantil: o } \\
\text { que dizem as crianças? }\end{array}$ & $\begin{array}{l}\text { Rafaely Karolynne do } \\
\text { Nascimento Campos }\end{array}$ & Dissertação & 2017 & UFS & Nordeste \\
\hline
\end{tabular}

Fonte: Elaborado pelas autoras (2020)

O quadro apresentado evidencia a localização das produções em apenas duas regiões brasileiras (Nordeste e Sudeste), vinculadas em uma universidade de cada uma dessas regiões (Universidade Federal de Sergipe - UFS e Universidade Estadual Paulista - UNESP/Campus de Presidente Prudente).

Consideramos importante destacar, à vista disso, que os dois trabalhos realizados na UNESP foram orientados pelo mesmo professor (Dr. José Milton de Lima); o mesmo se repete na UFS, onde as duas dissertações foram orientadas pela Profa. Dra. Tacyana Carla Gomes Ramos. Tal quadro, alinhado ao fato de que em ambos os programas não há linhas de pesquisa específicas sobre o tema em questão, leva-nos a pensar que o interesse por investigações sobre o brincar e temáticas correlatas são pontuais, localizadas em pesquisadores bastante específicos. 
Isso posto, a seguir apresentamos uma síntese das ideias gerais encontradas nas produções analisadas.

\section{Alguns achados da pesquisa}

O primeiro ponto que merece destaque refere-se à abordagem teórica adotada pelos trabalhos selecionados, sendo possível notar que as pesquisas evidenciam duas tendências no que tange o embasamento teórico que as norteiam; duas relacionam-se às discussões da Sociologia da Infância e as outras duas à teoria histórico-cultural.

No que diz respeito ao tipo de pesquisa, prevalece a pesquisa empírica, abordagem que, entendemos, permite a construção de dados mais alinhados à realidade cotidiana concreta e objetiva. As quatro produções produziram dados a partir de um contato direto com o campo de estudo com uso, principalmente do recurso de observações in loco, em instituições de Educação Infantil.

Evidenciamos que, entre as produções analisadas, três adotam como participantes do estudo crianças entre 3 e 5 anos e uma com a faixa etária de 0 a 5 anos.

Com relação ao objeto e/ou concepção, duas tratam da concepção de brincadeira; uma dedica-se a discutir brinquedo e a outra o brincar. Sublinhamos que umas fazem a discussão de forma mais ampla e outras com destaques sucintos; mas, em todas as produções fica evidente a defesa da importância do brincar (e concepções correlatas) para o pleno desenvolvimento humano. Tais apontamentos evidenciam a polissemia que envolve os termos brincar, brinquedo, jogo e brincadeira.

Acerca da concepção brincadeira é possível acentuar uma aproximação entre as quatro produções, Santos (2010), Silva (2012), Almeida (2015) e Campos (2017), uma vez que todas reconhecem a brincadeira como elemento da cultura, construção social e como espaço de interação.

Para Santos (2010) a brincadeira é um elemento cultural, com argumentos ancorados na perspectiva do RCNEI (BRASIL, 1998), destaca-a como uma atividade fundamental para o desenvolvimento da identidade e da autonomia da criança, além de ser caminho para a promoção de capacidades como a atenção, a imaginação, a imitação entre outras.

Já para Silva (2012) a dinâmica em questão é tomada como elemento da cultura humana, que possibilita a criança apropriar-se do mundo:

[...] a brincadeira favorece o desenvolvimento cultural das crianças, já que é por meio dela que a criança, também, se apropriará das objetivações humanas. A brincadeira é a forma específica da criança de apropriar-se do mundo e de constituirse enquanto sujeito. A brincadeira influencia o desenvolvimento psíquico favorecendo a formação da imaginação ativa, capacitando a criança a dominar conhecimentos, funções sociais e normas de comportamentos. (SILVA, 2012, p. 77).

Almeida (2015) entende o brincar como uma característica inerente à criança, bem como espaço que viabiliza a aprendizagem e a liberdade de expressão, já que através dele a criança externa desejos e dá pistas de suas vivências concretas:

[...] nessa atividade elas compartilham e produzem, com os pares, sentidos e significados para o mundo vivenciado. Nesse sentido, o brincar é um espaço de aprendizagens, de liberdade, de criação e de expressão que também ajuda na estabilidade emocional, permitindo às crianças lidar com o medo, a angústia, a surpresa, o abandono e o poder. (ALMEIDA, 2015, p. 127). 
Campos (2017), por sua vez, trata a brincadeira concebida como uma construção social, considerando-a como "[...] uma atividade dotada de significação social, que supõe contexto social e cultural, necessitando de aprendizagem”. (CAMPOS, 2017, p. 31).

Como anunciado anteriormente todas as produções abordam o brincar. Mas, temos também em uma delas uma discussão sobre o brinquedo - com amparo teórico em Gilles Brougère (2004) -, entendido como "[...] um objeto cultural que carrega em seu cerne aspectos sociais, econômicos e políticos, o qual permite verificar, inclusive, as visões de criança e de infância de uma determinada sociedade". (SANTOS, 2010, p. 159); a autora ainda indica o brinquedo como uma ferramenta que dá suporte ao jogo/brincadeira.

A importância do jogo, da brincadeira e/ou da ludicidade é evidenciada em todos os trabalhos selecionados; as produções, na sua totalidade, proporcionam valiosas reflexões acerca da magnitude e complexidade que envolve a temática de forma geral.

De igual maneira, todos os trabalhos também afirmam e concordam sobre o papel de mediador do professor da Educação Infantil; bem como defendem a importância e necessidade de formação específica deste profissional para que ele esteja apto a fomentar o processo de desenvolvimento integral da criança a partir de vivências verdadeiramente lúdicas.

Nessa direção, salientamos o argumento contido nos trabalhos, e que coadunamos, de que a formação precisa ser organizada no sentido de instrumentalizar o professor para ser capaz de construir novos conceitos e desconstruir práticas arraigadas de maneiras equivocadas no contexto pedagógico. De forma complementar, Almeida (2015) assinala que os equívocos cometidos são preceitos de uma Pedagogia Tradicional que norteiam grande parte das ações dos educadores, fazendo com que estes acreditem em uma "normatividade" ideal, levando-os a enxergar somente o que falta na criança, mirando o que deve se tornar e não o que já é hoje.

Santos (2010) busca enaltecer a importância do brincar como ferramenta imprescindível à promoção do desenvolvimento infantil, argumentando que por meio do brincar a criança tem oportunidade de vivenciar e aprender sobre o mundo à sua volta e a cultura que o rege. Utilizando os argumentos de Müller e Carvalho (2009 apud SANTOS, 2010, p. 92) indicam que:

\footnotetext{
Brincar, portanto, deixa de ser somente um direito para se tornar o espaço de liberdade, de criação. Através da brincadeira a criança mergulha na vida, criando um espaço que expressa, que atribui sentido e significado aos acontecimentos. Brincar também é uma forma de buscar estabilidade emocional, pois certas brincadeiras trazem os elementos necessários para lidar com os medos, a angústia, a surpresa, o abandono, o poder, que são emoções necessárias ao convívio coletivo, ao convívio de pares. Brincar, como uma atividade compartilhada, permite ao ser humano conhecer e reinventar, "reproduzir e interpretar", gerando novas formas culturais entre as crianças. Através do brinquedo, a criança também tem acesso ao passado e ao futuro, revitalizando e inventando o mundo que almeja. Por isso, a atividade lúdica não pode ser pensada fora do contexto social e cultural da infância.
}

Um outro foco na análise dos trabalhos foi a concepção de criança adotada. Neste ponto, observamos que o trabalho de Silva (2012) a aborda de forma explícita; mas, levando em consideração a linha da teoria histórico-cultural que apoia a pesquisa, bem como a abordagem e amparo teórico bibliográfico utilizado, é possível inferir que o autor compreende a criança como sujeito ativo, que se constrói na relação com o mundo que o cerca, confirmado pelo recorte abaixo, que nos possibilita constatar tal inferência:

Por isso, é preciso frisar que a Educação Infantil não pode ir ao encontro de práticas escolarizantes [...] defendemos uma formação humana e emancipatória a nossas crianças que lhes dê condições para conhecer, refletir e buscar e/ou até mesmo reivindicar melhores condições de vida, inclusive 
de trabalho, no seu processo interminável de humanização. (SILVA, 2012, p. $68)$.

Santos (2010) segue os pressupostos da teoria histórico-cultural, que reconhece a criança como sujeito ativo, que tem nas relações que se estabelecem e na mediação do educador premissas para o desenvolvimento pleno de suas capacidades. Desta forma, afirma que

[...] o referencial teórico da pesquisa encara as crianças como sujeitos criativos, inteligentes, capazes de interagir, interpretar e apropriar-se ativamente dos aspectos da cultura com a qual compartilham, portanto, são geradores de culturas e corresponsáveis pelo seu processo de socialização e humanização. (SANTOS, 2010, p. 155).

No que tange à ideia e compreensão de criança de Almeida $(2015$, p. 10), a referida autora a descreve como sujeito ativo e capaz, que a partir de suas vivências registra suas impressões na sociedade em que está inserida:

A criança é considerada um sujeito falante, atuante e que vive experiências, com a sua própria visão a respeito do contexto histórico-social no qual se encontra e interage. Ela contribui na construção de significados, participa na renovação cultural e na constituição de costumes próprios. Ao mesmo tempo, é produtora e reprodutora do meio no qual está inserida.

Por sua vez, Campos (2017), cuja pesquisa buscou amparo no campo da Sociologia da Infância, assume a concepção de criança como "[...] ator social sujeito histórico-cultural, potagonista do seu processo de socialização" (CAMPOS, 2017 p. 143), que produz cultura fundamentada na relação entre os seus pares.

Em síntese, podemos afirmar que as produções analisadas vão à mesma direção, pois, em linhas gerais, reconhecem a criança como sujeito ativo e de diretos, que se desenvolve segundo suas interações e que produzem cultura. Além de que são unânimes ao reconhecer a importância do brincar frente ao desenvolvimento integral da criança e a Educação infantil como meio promotor, facilitador deste desenvolvimento.

\section{Últimas considerações}

Mesmo partindo de um número tão reduzido de trabalhos, foi possível concluir, na busca inicial para composição do corpus de análise, que temáticas correlatas ao brincar têm ganhado espaço nas produções científicas. No entanto, quando se refere as investigações que debrucem o olhar sobre o subnível creche, com enfoque educacional, ainda há um longo caminho a ser percorrido para que esta ganhe o devido destaque. Ressaltamos que a Educação Infantil, de forma geral, é preterida ao constatarmos que há um grande fluxo das produções com foco nas séries iniciais do Ensino Fundamental.

Entre as produções analisadas, apenas uma tem como lócus o nível creche ( 0 a 3 anos), sendo que as demais abordam também a pré-escola. Percebemos que o interesse dos pesquisadores se concentra na faixa etária entre 3 a 5 anos, contemplando apenas a última etapa da creche, denominada em algumas regiões como maternal III.

Quais impressões podem ser construídas em relação ao fluxo das produções? Aventamos que é como se a criança da primeiríssima infância não merecesse notoriedade, que aquilo que lhe é peculiar não tem valor científico no campo da Educação. Posto isto, acreditamos ser esta a grande lacuna indicada nos achados da investigação.

Com base nas pesquisas analisadas, o que foi possível concluir concernente ao brincar, jogos, brinquedos e brincadeiras no espaço da Educação Infantil? Que as produções são unânimes ao reconhecer a importância do brincar no processo de desenvolvimento, assim 
como a necessidade de ser utilizado como ferramenta pedagógica para alcançar o que preconiza as leis e documentos norteadores no que se refere ao desenvolvimento integral das crianças.

Contudo, as pesquisas de Silva (2012) e Almeida (2015) nos demonstram que existe um longo caminho a percorrer para que o brincar, como preconizado, seja de fato inserido na prática e nas vivências pedagógicas cotidianas. Ambos os pesquisadores "denunciam" em alguns trechos de relatos das observações o distanciamento entre o real do ideal. As produções nos permitem entender que a importância e necessidade do brincar estão expressos nos discursos dos professores, mas nem sempre fazem parte da prática efetiva, das rotinas infantis e pedagógicas desenvolvidas no chão das instituições de Educação Infantil. Poder-seia, aqui, pensar na possibilidade de pesquisas de intervenção que auxiliassem os atores escolares a tornar suas práticas pedagógicas mais permeadas de jogos e brincadeiras conforme indicam os documentos oficiais.

Por fim, acreditamos que a pesquisa deixa como contribuição para a área a indicação de algumas lacunas investigativas, de objetos, abordagens e de lócus que precisam ser mais estudados. Considerando que utilizamos como corte temporal a BNCC, acreditamos ser necessário indicar, entrementes, a realização de pesquisas futuras, que busquem dados de como a BNCC está sendo interpretada e os reflexos delas nas práticas pedagógicas, uma vez que, de alguma forma, ela também traz em seu bojo uma ideia de práticas pedagógicas lúdicas.

Para encerrar, é importante afirmar que buscamos somar esforços com as produções selecionadas e nos posicionamos reconhecendo que a concepção de criança contemporânea trazida nos documentos precisa ser adotada nas práticas das instituições; bem como que esta criança defendida requer um atendimento que contemple suas especificidades e direitos, principalmente ao direito de brincar. Isto porque o brincar constitui a expressão máxima da criança, além de ser instrumento educativo por excelência.

\section{Referências}

ALMEIDA, S. E. S. Participação de crianças nas rotinas da educação infantil. 2015. 169f. Dissertação (Mestrado em Educação) - Universidade Federal de Sergipe, São Cristóvão, 2015. Disponível em: https://ri.ufs.br/handle/riufs/4753. Acesso em: 02 jun. 2021.

BARDIN, L. Análise de conteúdo. São Paulo: Edições 70, 2011.

BORBA. A. M. As culturas da infância nos espaços-tempos do brincar: estratégias de participação e construção da ordem social em um grupo de crianças de 4-6 anos. In: REUNIÃO ANUAL DA ANPED. 29, 2006. Anais [...]. Caxambu: Anped, 2006. Disponível em: https://www.anped.org.br/sites/default/files/gt07-2229.pdf. Acesso em: 02 jun. 2021.

BRASIL. Ministério da Educação e do Desporto. Secretaria de Educação Fundamental. Critérios para um atendimento em creches que respeite os direitos fundamentais das crianças. Brasília: MEC/SEF/COEDI, 1995.

BRASIL. Ministério da Educação e do Desporto. Secretaria da Educação Fundamental. Referencial Curricular Nacional para a Educação Infantil. Brasília: MEC/SEF, 1998.

BRASIL. Conselho Nacional de Educação. Resolução CEB nº. 01/1999. Fixa as Diretrizes Curriculares Nacionais para Educação Infantil. Diário Oficial da União, Brasília, Seção 1, p. 18, 13 de abril de 1999. 
BRASIL. Ministério da Educação. Secretaria da Educação Básica. Parâmetros nacionais de qualidade para a educação infantil. Brasília: MEC: SEB, 2006.

BRASIL. CNE/CEB. Resolução no . 5, de 17 de dezembro de 2009. Fixa as Diretrizes Curriculares Nacionais para a Educação Infantil. 2009.

BRASIL. Ministério da Educação. Secretaria de Educação Básica. Diretrizes Curriculares Nacionais para a Educação Infantil. Brasília: MEC/SEB, 2010.

BRASIL. Ministério da Educação. Secretaria da Educação Básica. Brinquedos e brincadeiras de creches: manual de orientação pedagógica. Brasília: MEC/SEB, 2012.

CAMPOS, R. K. N. Modos de brincar na educação infantil: o que dizem as crianças? 2017. 116f. Dissertação (Mestrado em Educação) - Universidade Federal de Sergipe, São Cristóvão, 2017. Disponível em: https://ri.ufs.br/handle/riufs/4829. Acesso em: 02 jun. 2021.

RODRIGUES, S. A. Viajando pela educação da primeiríssima infância: sentidos, crenças e valores que sustentam os saberes e as práticas pedagógicas na/da creche. 2016. 253f. Tese (Doutorado em Educação) - Universidade Estadual Paulista, Faculdade de Ciências e Tecnologia, Presidente Prudente, 2016.

ROMANOWSKI, J. P.; ENS, R. T. As pesquisas denominadas do tipo "Estado da Arte" em educação. Diálogo Educativo, Curitiba, v. 6, n.19, p. 37-50, set./dez. 2006. Disponível em: https://periodicos.pucpr.br/index.php/dialogoeducacional/article/view/24176/22872. Acesso em: 02 jun. 2021.

SANTOS, L. A. T. O brinquedo na educação infantil como promotor das culturas da infância e humanização. 2010. 170f. Dissertação (Mestrado em Educação) - Universidade Estadual Paulista, Faculdade de Ciências e Tecnologia, Presidente Prudente, 2010. Disponível em: https://repositorio.unesp.br/handle/11449/92256. Acesso em: 02 jun. 2021.

SILVA, J. R. A brincadeira na educação infantil: uma experiência de pesquisa e intervenção. 2015. 171f. Dissertação (Mestrado em Educação) - Universidade Estadual Paulista, Faculdade de Ciências e Tecnologia, Presidente Prudente, 2015. Disponível em: http://www2.fct.unesp.br/pos/educacao/teses/2012/jose-ricardo.pdf. Acesso em: 02 jun. 2021.

TRIVIÑOS, A. N. S. Introdução à pesquisa em Ciências Sociais: a pesquisa qualitativa em educação. São Paulo: Atlas, 1987. 